reviews. After merging similar questions, 104 were distributed for voting. From the 30 most popular uncertainties, the top 15 questions were prioritised in a facilitated workshop These include prevention and prediction of preterm birth, neonatal infection, lung damage, necrotising enterocolitis, preeclampsia, preterm premature rupture of the membranes, optimal neonatal feeding strategy, pain perception and management, a care package at neonatal discharge, emotional and practical support, attachment and bonding, and the best time for cord clamping.

Conclusions These priorities provide guidance to ensure that future research addresses questions that are important to service users and clinicians. Challenges for the priority setting partnership included maximising participation amongst people most affected by preterm birth, the breadth of the topic and securing input from an appropriate range of clinicians.

\section{PS-052a NEURODEVELOPMENTAL OUTCOME OF EXTREMELY PRETERM INFANTS AT 6.5 YEARS OF AGE; EXTREMELY PRETERM INFANTS STUDY IN SWEDEN (EXPRESS)}

${ }^{1} \mathrm{~F}$ Serenius, ${ }^{2} \mathrm{U}$ Ewald, ${ }^{3} \mathrm{~V}$ Fellman, ${ }^{4} \mathrm{M}$ Hafström, ${ }^{5} \mathrm{~K}$ Hellgren, ${ }^{6} \mathrm{~K}$ Källen, ${ }^{7} \mathrm{E}$ Lindberg, ${ }^{8} \mathrm{~K}$ Marsal, ${ }^{9} \mathrm{M}$ Norman, ${ }^{10} \mathrm{E}$ Olhager, ${ }^{11} \mathrm{~K}$ Stjernqvist, ${ }^{12} \mathrm{U}$ Åden, ${ }^{13} \mathrm{~A}$ Farooqi, ${ }^{2} \mathrm{~B}$ Strömberg. 'Women's and Children's Health, Uppsala University, Uppsala, Sweden; ${ }^{2}$ Pediatrics, Uppsala University, Uppsala, Sweden; ${ }^{3}$ Pediatrics, Lund University, Lund, Sweden; ${ }^{4}$ Pediatrics, Sahlgrenska University Hospital, Göteborg, Sweden; ${ }^{5}$ Ophthalmology, Karolinska University Hospital, Stockholm, Sweden; ${ }^{6}$ Centre for Reproductive Epidemiology, Lund University, Lund, Sweden; ${ }^{7}$ Pediatrics, Örebro University, Örebro, Sweden; ${ }^{8}$ Obstetrics Gynecology, Lund University, Lund, Sweden; ${ }^{9}$ Pediatrics, Karolinska University Hospital, Stockholm, Sweden; ${ }^{10}$ Pediatrics, Linköping University, Linköping, Sweden; ${ }^{11}$ Psychology, Lund University, Lund, Sweden; ${ }^{12}$ Pediatrics, Karolinska University Hospital, Stockholm, Sweden; ${ }^{13}$ Pediatrics, Umeå University, Umeå, Sweden

\subsection{6/archdischild-2014-307384.350}

Background Active perinatal care increases the survival of extremely preterm infants but there are concerns that improved survival might increase the rate of disabled survivors.

Objective To determine neurodevelopmental outcome at 6.5 years of age in extremely preterm children (EPT, $<27$ weeks) in a Swedish National cohort.

Design/methods Poulation-based prospective cohort of all EPT children born in Sweden from April 1, 2004, to March 31, 2007. Survivors were assessed and compared with a term-born control group. Of 707 live-born infants, 69\% survived to 6.5 years. Intellectual ability was measured with WISC- IV and results were related to the mean and SD of the controls. Clinical examination and parental questionnaires were used for diagnosis of cerebral palsy, hearing and vision impairments.

Results At a median age of 78 months, 445 of 494 eligible EPT children $(90 \%)$ were assed (59 by chart review). The rates of cerebral palsy, moderate visual impairment, blindness and deafness were $9.2 \%, 5.2 \%, 2.0 \%$ and $0.7 \%$, respectively vs $0.0 \%$, $0.5 \%, 0 \%$ and $0 \%$, respectively among 370 controls. 364 EPT children and 369 controls were formally tested with WISC-IV. Intellectual impairment $<-2$ SD but $>-3 \mathrm{SD}$, and $<-3 \mathrm{SD}$ was $9 \%$ and $19 \%$, respectively vs $1.9 \%$ and $0 \%$, respectively among controls. In 445 EPT children either formally assessed or by chart review, the rates of moderate and severe neurodevelopmental disabilities were $19 \%$ and $11 \%$, respectively compared with $2.4 \%$ and $0 \%$, respectively among control children.

Conclusion Disability rates are comparable to similar studies that report lower survival rates.

\section{Feeding Regimen}

\section{PS-053 VARIABILITY IN ADIPOKINES PROFILE OF NEWBORNS AND THEIR MOTHERS AFTER DHA SUPPLEMENTATION IN PREGNANCY}

${ }^{1}$ E Martín Alvarez, ${ }^{1} \mathrm{M}$ Peña-Caballero, ${ }^{1} \mathrm{JA}$ Hurtado-Suazo, ${ }^{2} \mathrm{~N}$ Kajarabille, ${ }^{3} \mathrm{~F}$ Lara-Villoslada, ${ }^{2} \mathrm{JJ}$ Ochoa. ${ }^{1}$ Paediatric, Hospital Universitario Virgen de Las Nieves, Granada, Spain; ${ }^{2}$ Nutrition, Institute of Nutrition and Food Technology "José Mataix", Granada, Spain, ${ }^{3}$ R\&D Department, Lactalis Puleva, Granada, Spain

\subsection{6/archdischild-2014-307384.351}

Background/aims Most studies of DHA supplementation during pregnancy and infant development are focused on visual and neural development. However, scarce information is available about the influence of DHA supplementation on adipokines expression, which are related to adipose tissue metabolism and obesity.

Aim Evaluate the effect of DHA supplemented dairy drink consumption during pregnancy and breastfeeding on the expression of several adipokines in mothers (pregnancy, delivery and breastfeeding) and their newborns (birth and 2.5 months of age).

Methods 60 women were randomly assigned to two intervention groups: A) Control Group ( $\mathrm{n}=30)$; B) Supplemented Group ( $\mathrm{n}=30)$ : The women took 2 glasses/day of the supplemented drink (400 mg DHA/day). Dietary intervention began in week 28th of pregnancy and concluded when breastfeeding stopped. Samples of blood were obtained from: the mothers, the umbilical vein and artery; the newborn at 2.5 months postpartum. Adiponectin, resistin, leptin and active PAI-1 plasma levels were determined using a panel from Luminex xMAP technology. Results Adiponectin was higher in the supplemented group in umbilical cord artery, whereas active-PAI showed a lower value in this group, although we observed an increase in mother's blood during delivery. Resistin did not show any difference. Leptin was higher in the supplemented group in umbilical cord.

Conclusion The most noteworthy result is the effect of DHA supplementation in umbilical cord artery adipokine levels, increasing the adiponectin and decreasing the active PAI-1. In addition, active PAI-1 increases in mothers during delivery. It is also interesting the increase in the supplemented group of leptin.

\section{\begin{tabular}{|l|l}
\hline PS-054 & VSL\#3 SUPPLEMENTATION TO MOTHERS DURING
\end{tabular} PREGNANCY AND BREAST FEEDING IMPROVES COLICS AND REGURGITATION IN NEWBORNS, PERHAPS BY TGF-B MODULATION}

${ }^{1} \mathrm{ME}$ Baldassarre, ${ }^{2} \mathrm{P}$ Mastromarino, ${ }^{3} \mathrm{~A}$ Miccheli, ${ }^{4} \mathrm{M}$ Fanelli, ${ }^{1} \mathrm{~A}$ Dileone, ${ }^{1} \mathrm{P}$ Drimaco, ${ }^{1} \mathrm{~N}$ Laforgia. 'Department of "Scienze Biomediche ed Oncologia Umana"- Neonatology and NICU Section, University of Bari, Bari, Italy; ${ }^{2}$ Department of Public Health and Infectious Diseases, University "La Sapienza", Rome, Italy; ${ }^{3}$ Department of Chemistry, University "La Sapienza", Rome, Italy; ${ }^{4}$ Department of Internal Medicine and Public Health-Section of Nuclear Medicine-Medical Statistics, University of Bari, Bari, Italy

\subsection{6/archdischild-2014-307384.352}

Aim To evaluate the influence of maternal supplementation with VSL\#3 on digestive events in newborns and cytokines levels in colostrum and mature breast milk.

Methods This pilot double-blind, randomised, placebo-controlled clinical trial (clinicaltrials.gov: NCT01367470) enrolled four weeks before expected delivery healthy pregnant women that received daily oral VSL\#3 (PTM) or placebo (CM) supplementation until four weeks after delivery. In milk samples we 
measured IL10 and TGFb (with commercial ELISA kits) at birth (T0) and after 30 (T30) days. Stool frequency and consistency (Bristol stool scale), regurgitation/vomiting, colics (Rome III criteria) in newborns were recorded in a weekly diary.

Two-way ANOVA for repeated measures, Chi-square test and RR: evaluation of time effect and link between probiotic supplementation and colics/ regurgitation.

Results 67 mothers/term newborns pairs were enrolled. In 44 milk samples we measured TGFb and IL10 with a significant increase in TGFb from T0 to T30 in PTM and a reduction in $\mathrm{CM}$ (interaction effect: $\mathrm{F}=10.314 \mathrm{p}=0.005$ ). IL10 was high at T0 and decreased in both groups at T30 (time effect: $\mathrm{F}=$ $25.808 \mathrm{p}<0.001)$. We found an higher frequency of colics and regurgitation in $\mathrm{CM}$ with respect to PTM newborns (colics: $\mathrm{c}^{2}$ $=7.2 \mathrm{p}=0.007 ; \mathrm{RR}=4$; regurgitations: $\mathrm{c}^{2}=6.944 \mathrm{p}=$ 0.008 ; RR $=2.43$ ). A TGFb modulation of muscarinic receptor involved in controls of intestinal motility could be hypotized. Regarding colics, VSL\#3 could be involved in pain perception. Conclusions VSL\#3 supplementation to mothers during pregnancy and breast feeding may be a powerful immune modulator in terms of $\mathrm{TGFb}$ in breast milk, and can influence intestinal motility and pain perception in newborns.

\section{PS-055 WHAT IS THE BEST POSITION FOR BOTTLE-FEEDING PRETERM INFANTS? A COCHRANE REVIEW}

${ }^{1} \mathrm{JA}$ Dawson, ${ }^{2} \mathrm{JP}$ Foster, ${ }^{3} \mathrm{SE}$ Jacobs, ${ }^{3} \mathrm{LR}$ Myers. ${ }^{1}$ Newborn Research, The Royal Women's Hospital, Parkville Melbourne, Australia; ${ }^{2}$ School of Nursing and Midwifery, University of Western Sydney, Sydney, Australia; ${ }^{3}$ Neonatal Services, The Royal Women's Hospital, Parkville Melbourne, Australia

\subsection{6/archdischild-2014-307384.353}

Background During sucking feeds preterm infants have been shown to experience physiological instability, including lower oxygen saturations $\left(\mathrm{SpO}_{2}\right)$ and heart rates $(\mathrm{HR})$, and periods of apnoea or cyanosis. Obstructive apnoea may occur when the infant's neck is hyperflexed or conversely, hyperextended. It has been hypothesised that airway obstruction linked to feeding position might be a contributing factor to a lower $\mathrm{SpO}_{2}$ and $\mathrm{HR}$. The aim of this Cochrane review was to assess the available evidence on the effect of position when bottle feeding preterm infants.

Method We performed a systematic review using the methodology of the Neonatal Review Group of the Cochrane Collaboration. An extensive search of electronic databases (Cochrane Central Register of Controlled Trials, MEDLINE, EMBASE and CINAHL) and trial registries has been performed.

Results Four small RCTs were identified that compared the standard cradle hold and alternate positions for feeding. In total 67 infants were studied One study did not report any of the $a$ priori outcome measures and was not included in the analysis. There were no difference between infants feed with a cradle hold versus a side lying position for the outcomes: days to achieve full suck feeding (MD $-4.00 ; 95 \%$ CI -9.20 to 1.20 , days), number of infants with an $\mathrm{SpO}_{2}<80 \%$ (RR 0.82; 95\% CI 0.53 to 1.28 ), $\mathrm{HR}<100 \mathrm{bpm}$ during feed (RR 2.00; 95\% CI 0.80 to 5.02 ), or time to complete feed (MD 4.00; $95 \%$ CI 1.02 to 9.02 , mins).

Conclusions There was no difference in infants' physiological stability between the cradle-hold and a side-lying position for bottle feeding preterm infants. Further research is required to determine if alternate positions to the cradle hold might be beneficial for bottle feeding preterm infants.

\section{PS-056 \\ INCREASING AMINO ACID AND NON-PROTEIN ENERGY IN PRETERMS ON PARENTERAL NUTRITION: HIGHER RATE OF SEPSIS AND NO BENEFIT IN SHORT-TERM GROWTH}

${ }^{1} \mathrm{C}$ Biagetti, ${ }^{1} \mathrm{MP}$ Bellagamba, ${ }^{1} \mathrm{R}$ D'Ascenzo, ${ }^{1}$ I Burattini, ${ }^{2} \mathrm{PE}$ Cogo, ${ }^{1} \mathrm{VP}$ Carnielli. ${ }^{1}$ Division of Neonatology, Polytechnic University of Marche, Ancona, Italy; ${ }^{2}$ Cardiac Anaesthesial Intensive Care Unit, Bambino Gesù Children's Hospital, Italy

\subsection{6/archdischild-2014-307384.354}

Background and aims We compared the effect of 3 parenteral nutrition $(\mathrm{PN})$ regimens on the short-term growth of the preterm infant $(\mathrm{PI})$.

Methods We randomised 220 PI with $\mathrm{BW}^{-1} \cdot \mathrm{d}-1[$ Non-Protein Energy NPE $=68 \mathrm{Kcal} \cdot \mathrm{kg}<$ sup-1.d-1]), HPSE (AA3.5, Glu 12, Fat $2.5 \mathrm{~g}^{\mathrm{kg}}{ }^{-1} \cdot \mathrm{d}-1\left[\mathrm{NPE}=68 \mathrm{Kca}^{-1} \mathrm{~kg}^{-1} \mathrm{~d}-1\right]$ ) or HPHE (AA3.5, Glu 14, Fat $\left.3.5 \mathrm{~g}^{\mathrm{kg}}{ }^{-1} \cdot \mathrm{d}-1[\mathrm{NPE}=85 \mathrm{Kcal} \cdot \mathrm{kg}-1 . \mathrm{d}-1]\right)$. PN was started at $1 \mathrm{~h}$ of life and intakes were increased to reach targets on day 4. The primary outcome was weight gain from birth to 36 W PMA.

Results Birth demographics and anthropometry were similar between groups. Administered AA, Glu and Fat intakes were significantly different among groups by study design. Growth data are in the Table below. There were no significant differences in the major complications of prematurity, except for Sepses occurring from day 4 to 28: SPSE 12/72 (12\%), HPSE 9/74 (12\%), HPHE 23/74 (31\%), $\mathrm{p}=0.01$.

SPSE $(\mathrm{n}=72)$ HPSE $(\mathrm{n}=74)$ HPHE $(\mathrm{n}=74) \mathrm{pAge}$ at nadir of body weight (days) $4.6 \pm 2.34 .1 \pm 1.63 .9 \pm 1.50 .07$ Weight loss at nadir (\% of BW) $12.5 \pm 5.611 .3 \pm 4.711 .8 \pm$ 5.9 0.4 Time from Birth to the Regained BW (days) $12.3 \pm 4.5$ $10.8 \pm 4.310 .7 \pm 5.0$ 0.07 Weight Gain from birth to $36 \mathrm{~W}$ PMA (g·kg-1?d-1) $15.6 \pm 2.016 .2 \pm 2.315 .7 \pm 2.30 .2$

Conclusions Increasing AA Intake from 2.5 to $3.5 \mathrm{~g} \cdot \mathrm{kg}^{-1} \cdot \mathrm{d}^{-1}$ with 68 or $85 \mathrm{Kcal}^{-1} \mathrm{~kg}^{-1} \cdot \mathrm{d}^{-1}$ of NPE did not improve (statistically and biologically) short-term growth. HPHE Infants had a significantly higher rate of sepsis. The alleged benefits of enhancing AA-Energy during PN for the PI should be carefully balanced against the odd of increasing infections.

\section{PS-057 ANALYSIS OF PROLONGED JAUNDICE IN NEWBORNS: A STUDY LOOKING AT THE INVESTIGATIONS PERFORMED AND OUTCOMES IN A DISTRICT GENERAL HOSPITAL}

G Hendriks, W Gao, H Bentur. Department of Paediatrics, St. Helen's and Knowsley NHS Trust, Liverpool, UK

\subsection{6/archdischild-2014-307384.355}

Background and aims Prolonged neonatal jaundice is a common presentation in newborns and rarely requires intervention; however it is important to rule out sinister causes such as biliary atresia. The outcome of this study was to analyse the demographics of infants presenting with prolonged jaundice, investigations undertaken and results of these tests in relation to NICE guidelines.

Methods We retrospectively identified infants over 2 years (January 2012 to December 2013) coded to have a prolonged jaundice screen. Analysing the case notes, 90 infants had a screen performed, from age 14 to 71 days of life, with an average of 21 days of life.

Results Of the infants screened, 18 (20\%) patients were found to have abnormal initial results, with significant abnormalities in 